\title{
Effect of Low Temperature on the Fabrication of Microring Resonator by Wet Etching
}

\author{
Hazura Haroon, Sahbudin Shaari, P. Susthitha Menon, \\ Burhanuddin Yeop Majlis, Hanim Abdul Razak and Mardiana Bidin \\ Institute of Microengineering and Nanoelectronics, \\ Universiti Kebangsaan Malaysia, 43600 Bangi, Selangor, Malaysia
}

Received 2012-04-17, Revised 2012-10-11; Accepted 2012-11-07

\begin{abstract}
Research related to semiconductor devices often relies on wafer fabrication. The fabrication of Silicon (Si) based devices by anisotropic wet etching can be affected by many etching parameters such as etching temperature, crystal orientation and percent of composition. Most of the anisotropic wet etchings by KOH solution done before were conducted at temperature over $70^{\circ} \mathrm{C}$. We found that the temperatures are not suitable to fabricate ring waveguide as the waveguide wall will collapse at such high temperature. This study reports the etching characteristics of $\mathrm{Si}<100\rangle$ in $\mathrm{KOH}$ solution with $35 \%$ concentration at the temperature below $70^{\circ} \mathrm{C}$. The etched wafer is targeted to be the basic structure for Microring Resonators (MRRs) based devices. This technique provides not only lower cost as compared to other etching technique, but also simple preparation. We found that low temperature manage to mold a good ring waveguide with low tendency to form rectangular structure due to crystal orientation. At $40^{\circ} \mathrm{C}$, the best waveguide formation was obtained with a smooth waveguide surface, experiencing an etching rate of $0.066 \mu \mathrm{min}^{-1}$ and an appreciable ring waveguide structure. The effect of the low temperature on the fabrication of the MRRs devices has been investigated and studied.
\end{abstract}

Keywords: Optical Waveguide Fabrication, Silicon Photonics, Anisotropic Chemical Etching, Microring Resonator, Optical Filters

\section{INTRODUCTION}

Microring Resonators (MRRs) are of great interest for integrated optoelectronic applications due to a number of reasons; compact size, simple design and high wavelength selectivity. Its application in diverse field such as optical communications system, biochemical sensing and laser systems make it a prime selection in the design of optoelectronic devices. Among the devices that can be designed using the MRRs is filters, modulators and delay line (Hazura et al., 2010; Shaari et al., 2010). Most of these devices can be realized by optical waveguides where it forms the basic structure for device construction. The simplest configuration of a MRRs device consists of one straight waveguide and one circular waveguide, also known as ring resonator as shown in Fig. 1. This configuration is commonly used in MRRs filter. The rib waveguide width for the circular waveguide, $W_{R}$ and the straight waveguide, $W_{S}$ designed in this study are $4 \mu \mathrm{m}$ and the gap distance between the straight and circular waveguides is $1 \mu \mathrm{m}$.

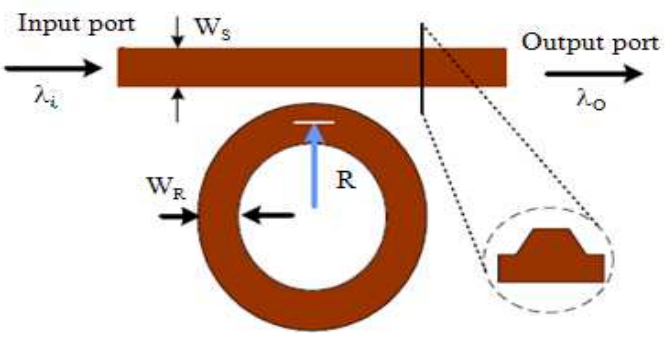

Fig. 1. Schematic diagram of the MRR illustrated the cross-section of the MRR waveguide

Corresponding Author: Hazura Haroon, Institute of Microengineering and Nanoelectronics, Universiti Kebangsaan Malaysia, 43600 Bangi, Selangor, Malaysia 


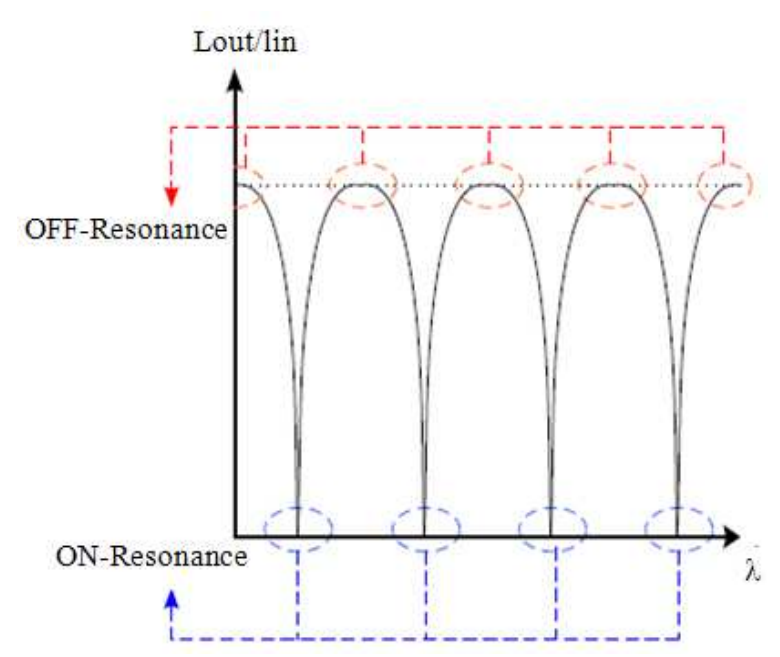

Fig. 2. Transmission spectra of MRRs filter

A typical transmission spectrum of MRRs is depicted in Fig. 2. Resonances occur when the resonant condition as given below is satisfied (Schweb, 2004):

$$
\mathrm{n}_{\text {eff }} \mathrm{L}=\mathrm{m} \lambda_{\mathrm{o}}
$$

where, $n_{\text {eff, }} m$ and $\lambda_{0}$ represent the effective refractive index of the mode guided inside the ring, resonant order and resonant wavelength, respectively. $\mathrm{L}$ is the circumference of the ring and can be calculated by $2 \pi R$.

If Eq. 1 is not satisfied, the microring will as a condition known as OFF resonance. At OFF-resonance state, the guided wave will bypass the ring and emitted at the output port. Upon the occurrence of resonant, the guided wave in the bus waveguide will be coupled to the ring and eventually the power observed at the output port will be depleted. This condition can be explained from the simulated result obtained from commercially available software by RSoft Inc. as presented in Fig. 3.

Theoretically, power transmission at the output port or through port can be predicted by Eq. 2 (Xioa et al., 2007; 2008):

$$
\mathrm{T}_{\text {through }}=\frac{\left(\lambda-\lambda_{\mathrm{o}}\right)^{2}+\left(\frac{\mathrm{FSR}}{4 \pi}\right)^{2}\left(\kappa_{\mathrm{p}}^{2}\right)^{2}}{\left(\lambda-\lambda_{\mathrm{o}}\right)^{2}+\left(\frac{\mathrm{FSR}}{4 \pi}\right)^{2}\left(2 \kappa^{2}+\kappa_{\mathrm{p}}^{2}\right)^{2}}
$$

Where:

$\lambda_{0}=$ The resonant wavelength

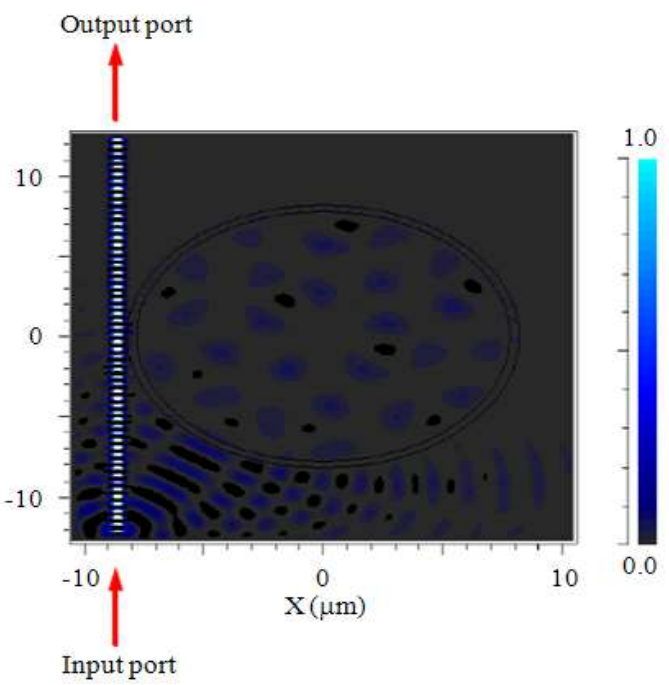

(a)

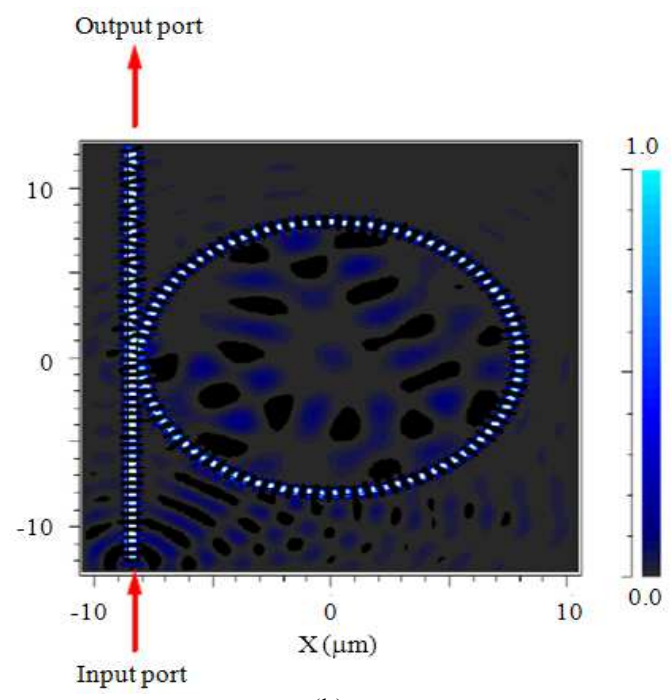

(b)

Fig. 3. Resonant condition of MRRs filter

$\kappa^{2}=$ The power coupling coefficient between the straight waveguide and the circular waveguide

$\kappa_{\mathrm{p}}^{2}=$ The propagation power loss coefficient per round trip in the microring resonator

FSR is one of the key parameters of the microresonator filters, which can be calculated by Eq. 3:

$$
\mathrm{FSR}=\frac{\lambda_{\mathrm{o}}^{2}}{\mathrm{n}_{\mathrm{eff}} \mathrm{L}} \approx \frac{\lambda_{\mathrm{o}}^{2}}{\mathrm{n}_{\mathrm{eff}}\left(2 \pi \mathrm{R}+2 \mathrm{~L}_{\mathrm{c}}\right)}
$$

where, $\mathrm{L}_{\mathrm{C}}$ is the coupler length. From the transmission spectrum as in Fig. 2, the FSR can be estimated by 
observing the difference between two consecutive resonant peaks. Since we will only focus on the fabrication process, FSR will be not discussed in details in this study.

To ensure the functionality of MRRs, both two waveguide structures must be formed properly. Fabrication of these devices on single-crystal Silicon (Si) wafer can be implemented using three main methods; wet etching, dry etching and laser writing.

Depending on the applications and specifications of the proposed device, each method has its own advantages and disadvantages. Fabrication based on anisotropic wet etching was selected in our study because of low cost factor and easy preparation.

Wet etching is a process where the substrate is being immersed into etchant solutions. Typically used etchants for Si include Potassium Hydroxide (KOH), thylenediamine-pyrocatechol-water (EDP) and hydrazine-water (Seidel et al., 1990). Hydrazine water and EDP handling must be done with special precaution because of its toxicity and instability. Despite being easily affected by several parameters such as crystals orientation, etching temperature and etchant concentration, $\mathrm{KOH}$ has excellent etching properties and nontoxic. For Si wafers with $<100>$ orientation, the rib waveguide with trapezoidal cross-section angle $\alpha=$ $54.74^{\circ} \mathrm{C}$ will be formed when soaked in $\mathrm{KOH}$ solution.

In this study, the etching process are conducted at temperature of $32,40,50,60$ and $70^{\circ} \mathrm{C}$ to study the effect of temperature on the surface roughness, etching rate and waveguide structures.

There are many research has been conducted previously to understand $\mathrm{KOH}$ wet etching, but most study performed at high temperature (over $60^{\circ} \mathrm{C}$ ) (Canavese et al., 2007). The purpose of this study is to discuss the characterization and the main issues arising in the $\mathrm{Si}$ waveguide fabrication process in the construction of MRRs device. Our focused is on the fabrication of MRR on Si using $\mathrm{KOH}$ wet etching at temperatures close to room temperature.

$\mathrm{Si}$ waveguide fabrication for MRRs device using $\mathrm{KOH}$ is the first in our best knowledge. The optical characterization of the device will not be discussed in this study. It should be emphasized that throughout this research, we assume that other parameters such as impurity concentration, bath condition and other contaminations are lightly influenced the fabrication performance.

\section{MATERIALS AND METHODS}

An n-type, $<100>$-oriented silicon wafer with $1 \sim 20 \Omega . c m$ resistivity was used as our substrates. Figure 4 illustrated the fabrication process. First, Si substrates were cleaned using standard cleaning procedure. Approximately $1200 \AA$ oxide layer was formed on the $\mathrm{Si}$ wafers using dry oxidation furnace by Carbolite after being exposed for $180 \mathrm{~min}$. The temperature for the $\mathrm{SiO}_{2}$ growth was $1000^{\circ} \mathrm{C}$. Through previous study (Hazura et al., 2012), the thickness is sufficient as a mask for Si photolithography process.

Positive photoresist PR1-1000A was then spincoated on top of the oxide layer at $3000 \mathrm{rpm}$ for $40 \mathrm{sec}$. This process followed by UV exposure where MRRs designs transferred onto the Si wafers. Afterwards, the Si wafer were immersed in RD6 developer from Futurex to remove unwanted resist and rinsed. The etching windows were formed by removing Silicon Dioxide $\left(\mathrm{SiO}_{2}\right)$ using Buffer Oxide Etch (BOE).

The wet etching process was then carried out using $35 \mathrm{wt} \% \mathrm{KOH}$ aqueous solution at temperature of 33, 40, 50,60 and $70^{\circ} \mathrm{C}$ without any agitation. Temperature $33^{\circ} \mathrm{C}$ is the minimum temperature measured when $\mathrm{KOH}$ solution was cooled down to room temperature. The etching process for all temperatures was performed for 15 min. Once completed, Si wafer were cleaned with deionized water to remove any residues of the process and dried using nitrogen gas.

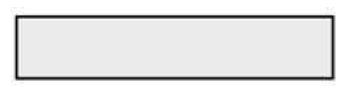

(a) Si substrate

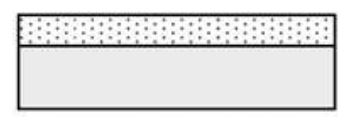

(b) $\mathrm{SiO}_{2}$ Deposition

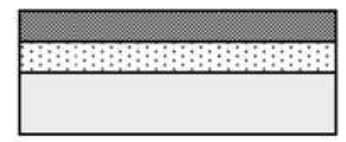

(c) Resist coating

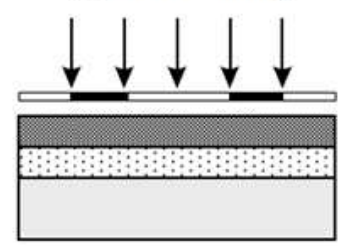

(d) UV Exposure

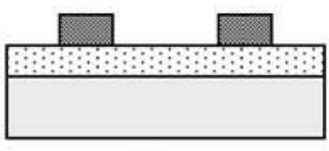

(e) Develop

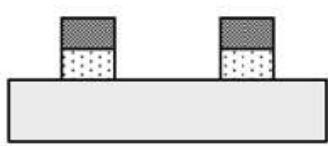

(f) BOE

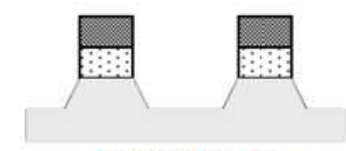

(g) $\mathrm{KOH}$ Etching

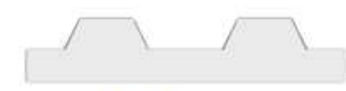

(h) Final clcaning

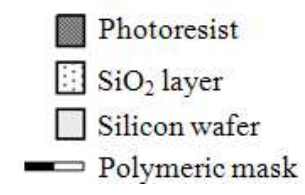

Fig. 4. Schematic diagram showing the fabrication process via $\mathrm{KOH}$ wet etching of $\mathrm{Si}<100>$ 


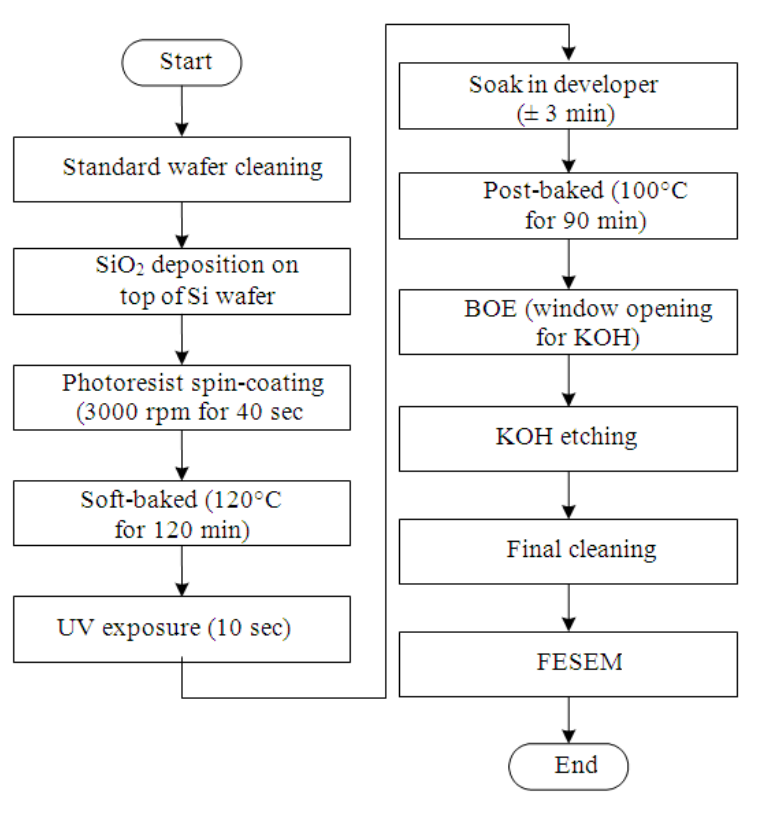

Fig. 5. Flow chart of the fabrication process

The morphological characterizations of the etched $\mathrm{Si}$ surfaces were then evaluated by means of Zeiss Supra Field Emission Scanning Electron Microscope (FESEM). The fabrication flow-chart of MRR is shown in Fig. 5.

\section{RESULTS}

Approximately $2 \mathrm{~cm}^{2}$ silicon substrates were used in these experiments. The wafers were soaked in $\mathrm{KOH}$ solution (concentration 35\%) for $15 \mathrm{~min}$ at 33, 40, 50, 60 and $70^{\circ} \mathrm{C}$. Etch depth for the straight waveguide was measured using FESEM and the etching rate was calculated. Summary of the silicon etching rate is shown in Table 1.

Table 1 depicts the relationship of $\mathrm{Si}<100>$ etching rate with $\mathrm{KOH}$ temperature. As the temperature increases, the etch rate is also raised.

We also compare the etch rate obtained with the other researchers works as depicted in Fig. 6 (please refer Wilke et al., 2005; Branislav and Marija, 2010; Kociubinski et al., 2009; Alves et al., 2005; Soin and Majlis, 2006). It was found that the etching rate of silicon was dependable on many parameters including the bath condition, the $\mathrm{KOH}$ concentrations. Temperature is only one of the contributing factors affecting the etch rate. Therefore, in our study, others factors are kept constant.
Table 1. Dependence of Etching rate on $\mathrm{KOH}$ temperature

\begin{tabular}{ll}
\hline $\mathrm{T}\left({ }^{\circ} \mathrm{C}\right)$ & Etching rate $\left(\mu \mathrm{min}^{-1}\right)$ \\
\hline 33 & 0.037 \\
40 & 0.066 \\
50 & 0.181 \\
60 & 0.322 \\
70 & 0.531 \\
\hline
\end{tabular}

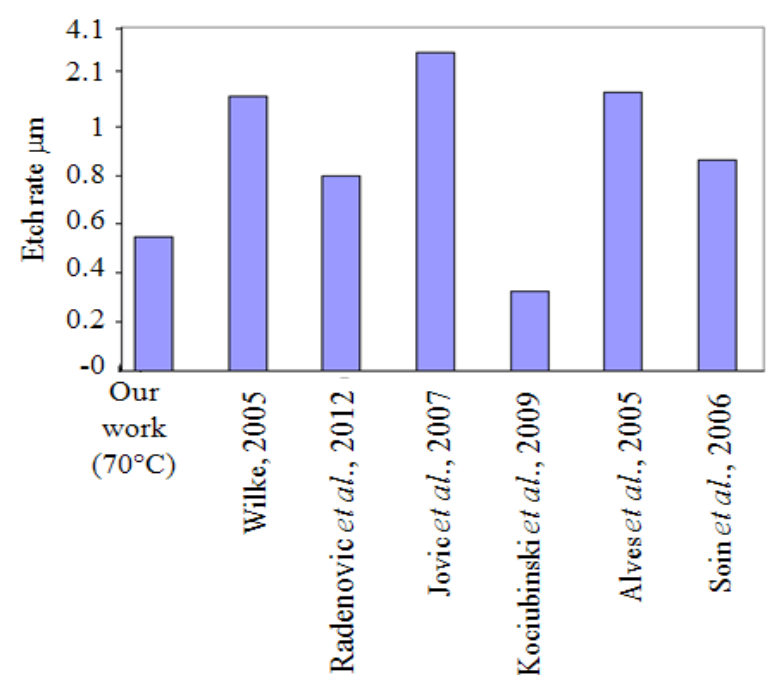

Fig. 6. Etch rate reported before with various etching parameters setup

Figure 7 depict the results of the side-wall surface roughness observed from the straight waveguide at $33^{\circ} \mathrm{C}$, 50 and $70^{\circ} \mathrm{C}$, respectively. It was found that an adequate surface roughness drop is observed at lower temperature.

Optical microscopy pictures of Fig. 8 were taken by observing the circular waveguide pattern from top view. It is shown that a well formed, acceptable circular waveguide structure can be mold at $\mathrm{T}=33^{\circ} \mathrm{C}$. However, the $\mathrm{Si}$ structure collapse gradually with an increase of etching temperature. The waveguide structure tends to shape into a rectangular at $40^{\circ} \mathrm{C}$. Since $\mathrm{KOH}$ etching dependable on the crystal orientation, this phenomenon is understandable. At $50^{\circ} \mathrm{C}$, half of the waveguide structure destroyed and the waveguide edge were totally break up at $60^{\circ} \mathrm{C}$ due to overetching.

\section{DISCUSSION}

Table 1 depicts the relationship of $\mathrm{Si}<100>$ etching rate with $\mathrm{KOH}$ temperature. We found that, higher temperature has the ability to etch Si faster, as example the etching rate improves $93 \%$ as we increase the temperature from $\mathrm{T}=32^{\circ} \mathrm{C}$ to $\mathrm{T}=70^{\circ} \mathrm{C}$. 
Hazura Haroon et al. / American Journal of Applied Sciences, 9 (12) (2012) 1922-1928

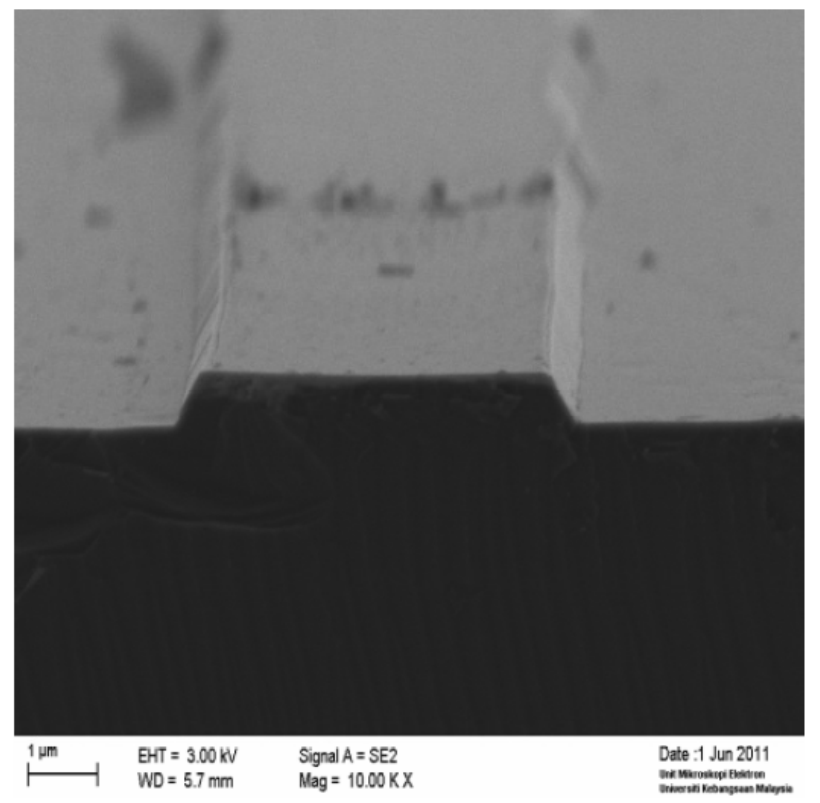

(a)

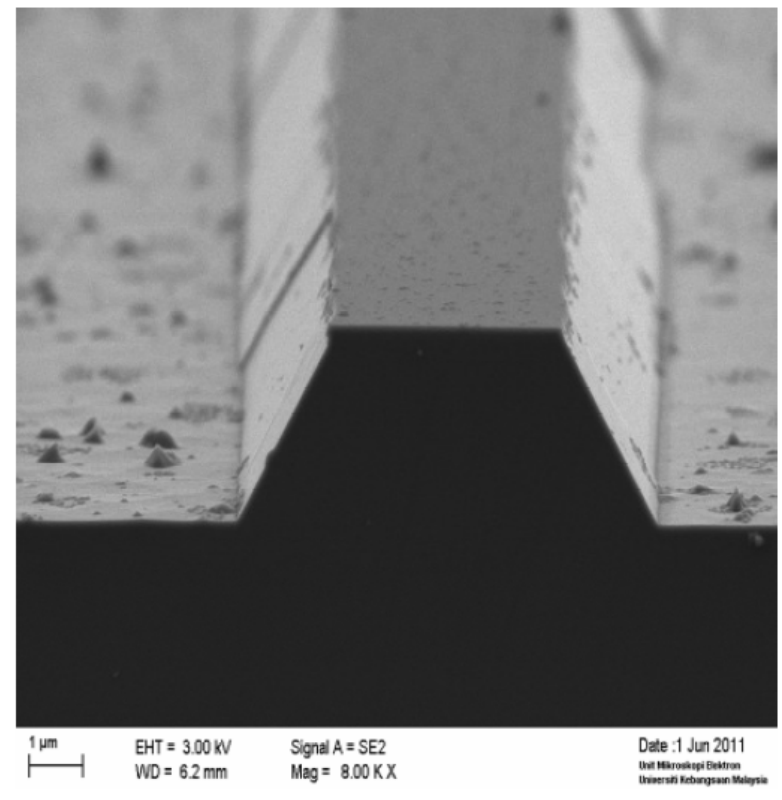

(b)

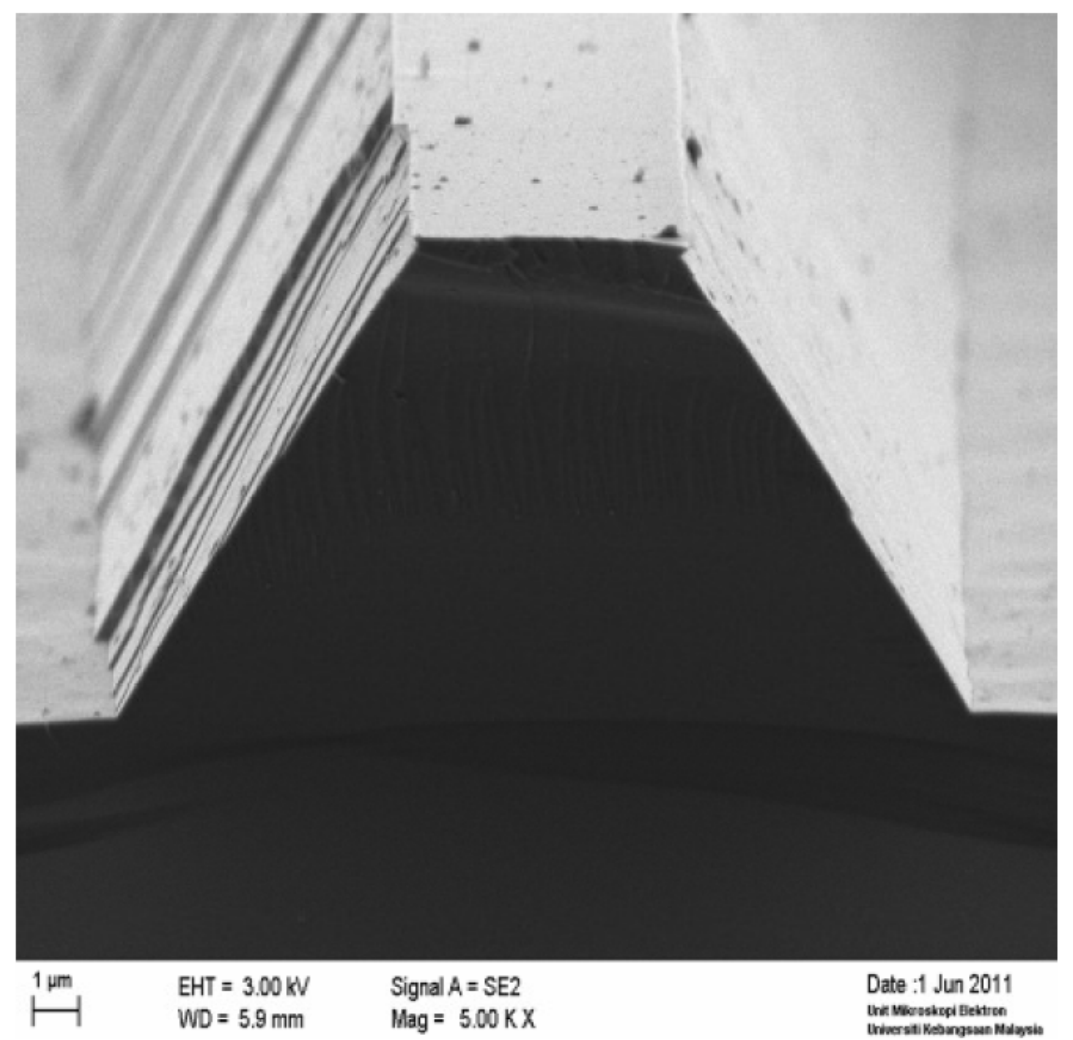

(c)

Fig. 7. FESEM photographs of straight waveguides at (a) $33^{\circ} \mathrm{C}$ (b) $50^{\circ} \mathrm{C}$ and (c) $70^{\circ} \mathrm{C}$ 


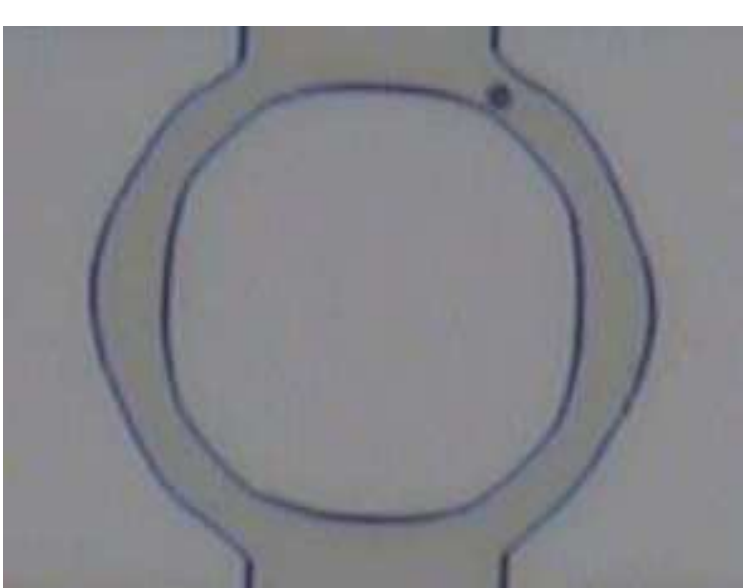

(a)

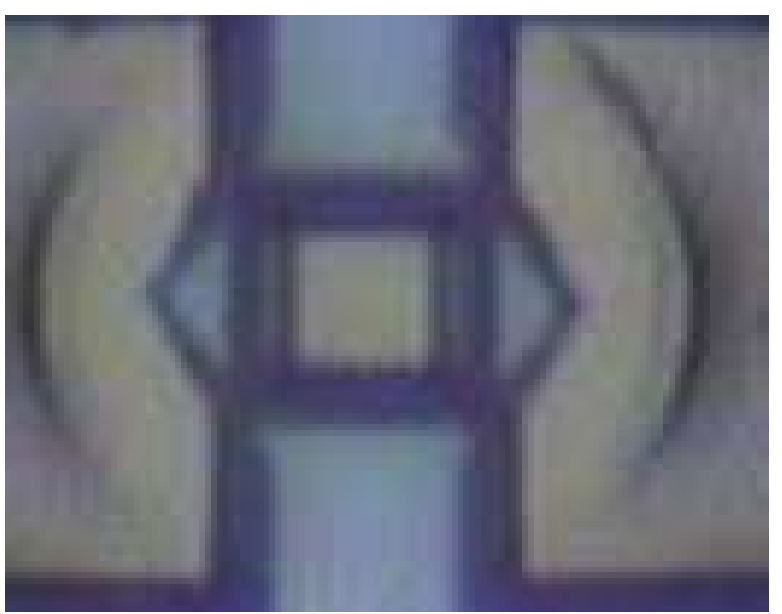

(c)

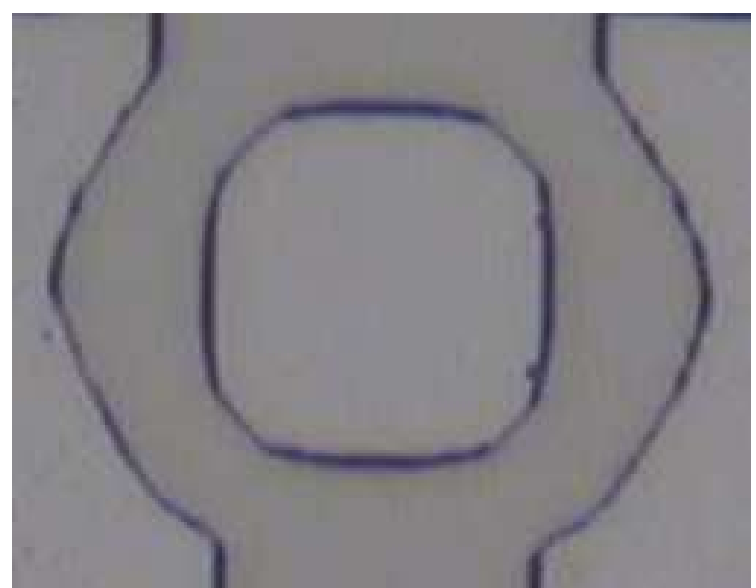

(b)

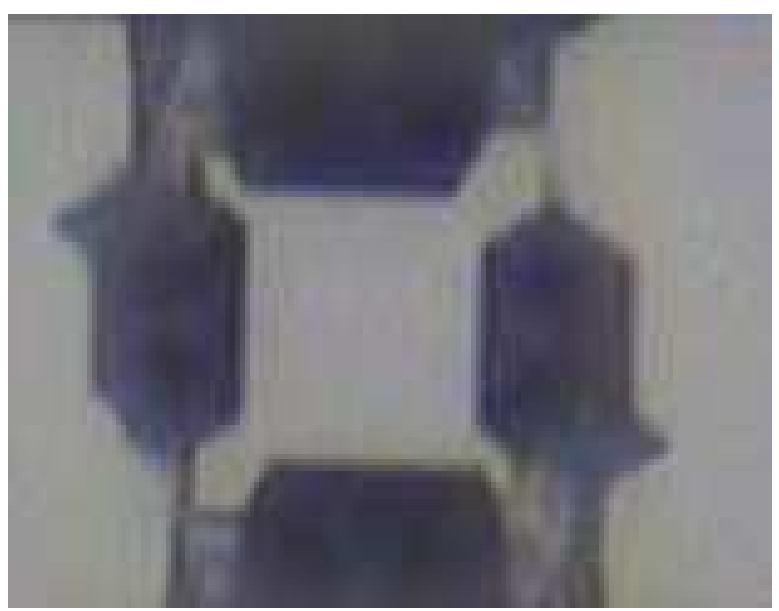

(d)

Fig. 8. Microscope pictures of circular waveguides at (a) $33^{\circ} \mathrm{C} \mathrm{(b)} 40^{\circ} \mathrm{C}$ (c) $50^{\circ} \mathrm{C}$ and (c) $60^{\circ} \mathrm{C}$ for 15 min etching time

Figure 6 portrays the etch rate reported before for $\mathrm{Si}$ $<100>$ with various temperatures, $\mathrm{KOH}$ concentrations and etching setup. Most of them were conducted at temperature over $70^{\circ} \mathrm{C}$. Those results imply that the etch rate is dependable on many parameters such as etching temperature, enchants concentrations and so forth. An accurate control in handling the $\mathrm{KOH}$ solutions is therefore desired to sustain the exact parameter values which will directly influence the etch rate.

From Figure 7, we can see that the side-wall surface roughens as the temperature gradually increased. The formation of so-called wavy sidewalls produced by higher temperature is expected to cause a scattering of light, which in MRRs manufacturing will resulting the reflection loss.
Figure 8 demonstrated that an acceptable etching temperature for circular waveguide formation is ranging from $33-40^{\circ} \mathrm{C}$.

\section{CONCLUSION}

The effect of low temperature on the physical performance of optical waveguide for fabrication of MRRs based devices has been studied. Results show that there must be a balance between the etching rate and surface roughness. As a good ring waveguide formation is compulsory in developing MRRS based devices, low temperature is more suitable to fabricate straight and ring waveguide. We can observe that higher temperature yield rough etching but faster etching rate. The best ring waveguide structure forms at 
$\mathrm{T}=40^{\circ} \mathrm{C}$. The efficiency of the fabrication process will be investigated by coupling the light input into the optical waveguide in our further research.

\section{ACKNOWLEDGMENT}

The researcher would like to thank Universiti Teknikal Malaysia Melaka (UTeM) for the support and to the staff of Photonic Technology Lab and Clean room of Institute of Microelectronic and Nanotechnology (IMEN), Universiti Kebangsaan Malaysia for assistance and guidance. The Ministry of Higher Education of Malaysia and Universiti Kebangsaan Malaysia (UKM) is gratefully acknowledged for the grant under industrial Project2011-015 and UKM-OUP-NBT-27-119/2011.

\section{REFERENCES}

1. Alves, M.A.R., D.F. Takeuti and E.S. Braga, 2005. Fabrication of sharp silicon tips employing anisotropic wet etching and reactive ion etching. Micro. J., 36: 51-54. DOI: 10.1016/j.mejo.2004.10.004

2. Branislav, R. and R.R. Marija, 2010. Level set simulations of the anisotropic wet etching process for device fabrication in nanotechnologies. Hem. Ind., 64: 93-97. DOI: 10.2298/HEMIND100205008R

3. Canavese, G., S.L. Marasso, M. Quaglio, M. Cocuzza and C. Ricciardi et al., 2007. Polymeric mask protection for alternative $\mathrm{KOH}$ silicon wet etching. J. Micromech. Microeng., 17: 1387-1393. DOI: 10.1088/0960$1317 / 17 / 7 / 022$

4. Hazura, H., A.R. Hanim, B. Mardiana, P.S. Menon, 2010. An analysis of silicon waveguide phase modulation efficiency based on carrier depletion effect. Proceedings of the IEEE International Conference on Semiconductor Electronics, Jun. 28-30, IEEE Xplore Press, Melaka, pp: 348-350. DOI: 10.1109/SMELEC.2010.5549519
5. Hazura, H., A.R. Hanim, B. Mardiana, S. Shaari and P.S. Menon, 2012. Process modeling, optimization and characterization of silicon $<100>$ optical waveguides by anisotropic wet etching. Adv. Mater. Res., 403-408: 4295-4299. http://www.scientific.net/AMR.403-408.4295

6. Kociubinski, A., M. Duk, Bieniek and P. Janus, 2009. Modeling, simulation and calibration of silicon wet etching. J. Telecomm. Inform. Technol., $\quad 4$ : 65-70. http://www.nit.eu/czasopisma/JTIT/2009/4/65.p $\mathrm{df}$

7. Schweb, O., 2004. Transmission, group delay and dispersion in single-ring optical resonators and add/drop filters-a tutorial overview. J. Lightwave Technol., 22: 1380-1394. DOI: 10.1109/JLT.2004.827666

8. Seidel, H., L. Csepregi, A. Heuberger and H. Baumgartel, 1990. Anisotropic etching of crystalline silicon in alkaline solutions. J. Electrochem. Soc., 137: 3612-3626. DOI: 10.1149/1.2086277

9. Shaari, S., A.R. Hanim, B. Mardiana, H. Hazura, P.S. Menon, 2010. Modeling and analysis of lateral doping region translation variation on optical modulator performance. Proceedings of the 4th Asian Physics Symposium AIP Conference, Oct. 12-13, AIP, West Java, pp: 297-300. DOI: 10.1063/1.3537933

10. Soin, N. and B.Y. Majlis, 2006. Development of perfect silicon corrugated diaphragm using anisotropic etching. Microelect. Eng., 83: 14381441. DOI: 10.1016/j.mee.2006.01.084

11. Wilke, N., A. Mulcahy, S.R. Ye and A. Morrissey, 2005. Process optimization and characterization of silicon microneedles fabricated by wet etch technology. Micro. J., 36: 650-656. DOI: 10.1016/j.mejo.2005.04.044

12. Xioa, S., M.H. Khan, H. Shen and M. Qi, 2007. Modeling and measurement of losses in siliconon-insulator resonators and bends. Optics Exp., 15: 10553-10561. DOI: 10.1364/OE.15.010553

13. Xioa, S., M.H. Khan, H. Shen and M. Qi, 2008. Silicon-on-insulator microring add-drop filters with free spectral ranges over $30 \mathrm{~nm}$. J. Lightwave Technol., 26: 228-236. DOI: 10.1109/JLT.2007.911098 